\title{
Penerapan Algoritma K-Means Clustering untuk Pengelompokan Harga Eceran Beras di Pasar Tradisional Berdasarkan Wilayah Kota
}

\author{
Theresia Siburian', M.Safii ${ }^{2}$, Iin Parlina ${ }^{2}$ \\ ${ }^{1}$ STIKOM Tunas Bangsa Pematangsiantar, Indonesia \\ ${ }^{2}$ AMIK Tunas Bangsa Pematangsiantar, Indonesia \\ 1,2Jln. Jendral Sudirman Blok A No.1/2/3, Pematangsiantar \\ siburiantheresia21@gmail.com
}

\begin{abstract}
Rice is the main food commodity of the Indonesian people, almost all residents in this country consume rice every day. This causes rice commodities to have a very strategic value, apart from being in control of the lives of many people, it can also be used as a parameter of the country's economic and social stability. This study discusses the application of K-Means Clustering Algorithm for Grouping Retail Prices of Rice in Traditional Markets. The source of this research data is collected based on documents describing the retail price group of rice produced by the National Statistics Agency. The data used in this study are data from 2011-2016 consisting of 33 cities. Data is processed by clustering in 3 clusters, namely high population level clusters, medium and low population level clusters. Centroid data for high population level clusters 10,776, Centroid data for moderate population level clusters 9,436 and Centroid data for low population clusters 8,590. To obtain an assessment based on the grouping of the average retail price of rice in traditional markets in 33 cities with high clusters (C1) of 11 cities namely Padang, Pekanbaru, Tanjung Pinang, Bandar Lampung, Jakarta, Pontianak, Palangkaraya, Banjarmasin, Ternate, Jayapura and Manokwari for medium cluster (C2) as many as 11 cities and for low cluster (C3) as many as 11 cities. From the results of this study can be used as input for the government, especially in cities, so that cities that are included in the high cluster can normalize the retail price of rice in each city area.
\end{abstract}

Keywords: Datamining, Clustering, Rice, K-means.

Abstrak- Beras merupakan komoditas pangan utama masyarakat Indonesia, hampir seluruh penduduk di negara ini mengkonsumsi beras setiap harinya. Hal ini menyebabkan komoditas beras memiliki nilai yang sangat strategis, selain karena menguasai hajat hidup orang banyak, juga dapat dijadikan parameter stabilitas ekonomi dan sosial negara. Penelitian ini membahas Penerapan Algoritma K-Means Clustering Untuk Pengelompokkan Harga Eceran Beras di Pasar Tradisional. Sumber data penelitian ini dikumpulkan berdasarkan dokumen-dokumen keterangan kelompok harga eceran beras yang dihasilkan oleh Badan Pusat Statistik Nasional. Data yang digunakan dalam penelitian ini adalah data dari tahun 2011-2016 yang terdiri dari 33 kota. Data diolah dengan melakukan clustering dalam 3 cluster yaitu cluster tingkat populasi tinggi, cluster tingkat populasi sedang dan rendah. Centroid data untuk cluster tingkat populasi tinggi 10.776, Centroid data untuk cluster tingkat populasi sedang 9.436 dan Centroid data untuk cluster tingkat populasi rendah 8.590. Sehingga diperoleh penilaian berdasarkan pengelompokan jumlah rata-rata harga eceran beras di pasar tradisional di 33 kota dengan cluster tinggi (C1) sebanyak 11 Kota yakni Padang, Pekanbaru, Tanjung Pinang, Bandar Lampung, Jakarta, Pontianak, Palangkaraya, Banjarmasin, Ternate, Jayapura dan Manokwari untuk cluster sedang (C2) sebanyak 11 Kota dan untuk cluster rendah (C3) sebanyak 11 Kota. Dari hasil penelitian ini 
dapat dijadikan masukan bagi pemerintah khususnya di kota, agar kota yang masuk kedalam cluster tinggi dapat menormalisasikan harga eceran beras di tiap-tiap wilayah kota.

Kata kunci: Datamining, Clustering, Beras, K-means.

\section{PENDAHULUAN}

Beras sebagai menu pokok utama yang selalu dikonsumsi oleh hampir seluruh masyarakat indonesia. Ini memiliki kandungan pati yang cukup besar dibandingkan dengan sereal. Selain itu, dalam beras juga mengandung vitamin, protein, mineral, dan air. Indonesia adalah negara terbesar ketiga yang memproduksi beras terbanyak di dunia, akan tetapi indonesia masih tetap perlu mengimpor sekitar 3 juta ton beras hampir setiap tahunnya, terutama dari thailand dan vietnam untuk menjaga tingkat cadangan beras dan beras sering kita temui di pasaran khususnya di pasar tradisional. Datamining merupakan proses menemukan korelasi baru yang bermanfaat, pola dan trend dengan menambang sejumlah repositori data dalam jumlah besar, menggunakan teknologi pengenalan pola seperti statistik dan teknik matematika. Datamining semakin menyebar dan berkembang dengan pesat belakangan ini karena kemampuannya dalam menambang pola bermanfaat dan trend dari basis data yang sudah ada. Perusahaan-perusahaan telah menghabiskan dana milyaran untuk mengumpulkan data dalam jumlah megabytes atau terabytes tapi tidak mendapatkan keuntungan yang bernilai di dalamnya, padahal didalamnya terdapat informasi yang berharga namun tersembunyi pada repositori data[1]. Menurut Daryl Pregibon bahwa datamining adalah campuran dari statistic, kecerdasan buatan, dan riset basis data yang masih berkembang[2].

Salah satu teknik pengelompokkan dalam data mining adalah metode clustering. Clustering adalah metode yang digunakan dalam data mining yang cara kerjanya mencari dan mengelompokkan data yang mempunyai kemiripan karakteristik antara data satu dengan data lainnya yang telah diperoleh. Ciri khas dari teknik data mining ini adalah mempunyai sifat tanpa arahan (unsupervised), yang dimaksud adalah teknik ini diterapkankan tanpa perlunya data training dan tanpa ada teacher serta tidak memerlukan target output[3]. Pada penelitian ini penulis menggunakan algoritma K-means yang merupakan metode clustering yang paling sederhana dan umum. Hal ini dikarenakan K-means mempunyai kemampuan mengelompokkan data dalam jumlah yang cukup besar dengan waktu komputasi yang relatif cepat dan efesien[4].

\section{METODOLOGI PENELITIAN}

\subsection{Data Mining}

Data mining adalah proses untuk menemukan pola atau pengetahuan bermanfaat secara otomatis dari sekumpulan data yang berjumlah banyak, data mining sering dianggap sebagai bagian dari Knowledge Discovery in Database (KDD) yaitu sebuah proses mencari pengetahuan yang bermanfaat dari data, proses KDD secara garis besar dilakukan dalam bentuk (1) Pemilihan Data (Data Selection), (2) Pra-proses (Pre-processing/Cleaning), (3) Transformasi (4) Sajian 
yang mudah (Transformation), (Interpretation/dimengerti dan Evaluasi (Evaluation)[5].

Menurut Prastyo (2012), data mining terbagi menjadi beberapa kelompok yaitu sebagai berikut:

a.Model Prediksi Pemodelan yang dapat melakukkan pemetaan dari setiap himpunan variabel ke setiap targetnya, kemudian menggunakan model tersebut untuk memberikan nilai target pada himpunan baru yang telah didapat.

b.Analisis Kelompok Mengelompokkan sekumpulan data ke dalam kelompok (cluster) tertentu berdasarkan karakteristik yang sama pada masing-masing data.

\section{c. Analisis Asosiasi}

Menentukan pola yang menggambar- kan kekuatan hubungan fitur dalam data.

d.Deteksi Anomaly Pengamatan suatu data dari sekumpulan data yang secara signifikan memiliki karakteristik yang berbeda dari sisa data yang lain[6].

Sebagai suatu rangkaian proses, data mining dapat dibagi menjadi beberapa tahap. Tahap-tahap tersebut bersifat interaktif di mana pemakai terlibat langsung atau dengan perantaraan knowledge base diantaranya adalah:

a. Pembersihan data (untuk membuang data yang tidak konsisten dan noise) b. Integrasi data (penggabungan data dari beberapa sumber)

c. Transformasi data (data diubah menjadi bentuk yang sesuai untuk di-mining)

d. Menentukan teknik data mining, yaitu teknik mencari pola dari hasil transformasi data.

e. Evaluasi pola yang ditemukan (untuk menemukan yang menarik/bernilai) $\mathrm{f}$. Presentasi pola yang ditemukan untuk menghasilkan aksi[7].

\subsection{Clustering}

Menurut Widodo (2013:9) Clustering atau klasifikasi adalah metode yang digunakan untuk membagi rangkaian data menjadi beberapa group berdasarkan kesamaan-kesamaan yang telah ditentukan sebelumnya. Cluster adalah sekelompok atau sekumpulan objek-objek data yang similar satu sama lain dalam cluster yang sama dan disimilar terhadap objek-objek yang berbeda cluster. Objek akan dikelomokkan ke dalam satu atau lebih cluster sehingga objek-objek yang berada dalam satu cluster akan mempunyai kesamaan yang tinggi antara satu dengan yang lainnya[8].

\subsection{Algoritma K-means}

Algoritma k-means adalah algoritma yang mempartisi data ke dalam clustercluster sehingga data yang memiliki kemiripan berada pada satu cluster yang yang memiliki data dan sama ketidaksamaan berada pada cluster yang lain[9].

Proses dasar algoritma k-means dapat dilihat di bawah ini :

1. Tentukan jumlah klaster yang ingin dibentuk dan tetapkan pusat cluster $\mathrm{k}$.

2. Menggunakan jarak euclidean kemudian hitung setiap data ke pusat cluster.

$$
\mathrm{d}(\mathrm{i}, \mathrm{k})=\sqrt{\sum_{i}^{m}(C i j+C k j)^{2}}
$$


3. Kelompokkan data ke dalam cluster dengan jarak yang paling pendek dengan persamaan

$$
\min \sum_{k}^{i}-a i k-=\sqrt{\sum_{i}^{m}(C i j+C k j)^{2}}
$$

4. Hitung pusat cluster yang baru menggunakan persamaan

$$
c k j=\sum_{k}^{i} \frac{x_{i j}}{p}
$$

Dengan : $\mathrm{X}_{\mathrm{ij} \epsilon}$ Kluster ke k p = banyaknya anggota kluster ke - $\mathrm{k}$

5. Ulangi langkah dua sampai dengan empat sehingga sudah tidak ada lagi data yang berpindah ke kluster yang lain[10].

\section{HASIL DAN PEMBAHASAN}

Dalam melakukan clustering, data yang diperoleh akan dihitung terlebih dahulu berdasarkan jumlah Rata-rata Harga Eceran Beras di Pasar Tradisional di 33 Kota (Rupiah/Kg). Hasil penjumlahan dari populasi tersebut dapat dilihat seperti yang ditunjukkan pada tabel 1.

Tabel 1. Data Alternatif Jumlah Rata-rata Harga Eceran Beras di Pasar Tradisional di 33 Kota (Rupiah/Kg)

\begin{tabular}{|l|c|c|c|c|c|c|}
\hline \multirow{2}{*}{$\begin{array}{c}\text { Kota Harga } \\
\text { Eceran }\end{array}$} & \multicolumn{6}{|c|}{ Rata-rata Harga Eceran Beras di Pasar Tradisional di 33 Kota } \\
& \multicolumn{7}{|c|}{ Rupiah/Kg) } \\
\cline { 2 - 7 } & $\mathbf{2 0 1 1}$ & $\mathbf{2 0 1 2}$ & $\mathbf{2 0 1 3}$ & $\mathbf{2 0 1 4}$ & $\mathbf{2 0 1 5}$ & $\mathbf{2 0 1 6}$ \\
\hline Banda Aceh & 8247 & 8606 & 9076 & 9330 & 9735 & 10244 \\
\hline Medan & 7726 & 8602 & 9179 & 9575 & 10147 & 10548 \\
\hline Padang & 9878 & 9620 & 9559 & 11713 & 12258 & 12789 \\
\hline Pekanbaru & 9601 & 9601 & 9886 & 11172 & 11712 & 12270 \\
\hline Tanjung Pinang & 8031 & 9786 & 10329 & 11365 & 12425 & 10573 \\
\hline Jambi & 7631 & 8710 & 9160 & 9684 & 10336 & 9644 \\
\hline Palembang & 7644 & 8407 & 8677 & 8877 & 9644 & 10371 \\
\hline Pangkal Pinang & 7667 & 8898 & 9291 & 9529 & 10752 & 9967 \\
\hline Bengkulu & 7556 & 8117 & 8402 & 9696 & 10419 & 11416 \\
\hline Bandar Lampung & 10575 & 8758 & 8974 & 9817 & 10200 & 13767 \\
\hline Jakarta & 9929 & 9037 & 9447 & 10027 & 11733 & 12414 \\
\hline Bandung & 7639 & 8406 & 8572 & 9018 & 10696 & 11231 \\
\hline Serang & 7761 & 7708 & 7931 & 8151 & 9151 & 10379 \\
\hline Semarang & 7183 & 8398 & 8792 & 9187 & 9902 & 9872 \\
\hline Yogyakarta & 7799 & 7902 & 8383 & 9062 & 9772 & 10249 \\
\hline Surabaya & 6498 & 8335 & 8795 & 9209 & 10132 & 9553 \\
\hline Denpasar & 8336 & 8647 & 9044 & 9316 & 10378 & 10581 \\
\hline Mataram & 6609 & 7705 & 7776 & 8576 & 9608 & 9721 \\
\hline Kupang & 8058 & 8436 & 8922 & 9128 & 9999 & 11085 \\
\hline Pontianak & 9117 & 9829 & 10327 & 10814 & 12013 & 12477 \\
\hline Palangkaraya & 10883 & 11006 & 10742 & 12421 & 14728 & 13814 \\
\hline Banjarmasin & 9344 & 10127 & 9960 & 11272 & 12533 & 12911 \\
\hline Samarinda & 8057 & 9054 & 9563 & 11088 & 11429 & 11248 \\
\hline Manado & 7678 & 8706 & 8901 & 9223 & 10470 & 11666 \\
\hline
\end{tabular}




\begin{tabular}{|l|c|c|c|c|c|c|}
\hline \multirow{2}{*}{$\begin{array}{c}\text { Kota Harga } \\
\text { Eceran }\end{array}$} & \multicolumn{6}{|c|}{ Rata-rata Harga Eceran Beras di Pasar Tradisional di 33 Kota } \\
& \multicolumn{7}{|c|}{ (Rupiah/Kg) } & \\
\cline { 2 - 7 } & $\mathbf{2 0 1 1}$ & $\mathbf{2 0 1 2}$ & $\mathbf{2 0 1 3}$ & $\mathbf{2 0 1 4}$ & $\mathbf{2 0 1 5}$ & $\mathbf{2 0 1 6}$ \\
\hline Gorontalo & 7015 & 8238 & 8398 & 8620 & 9362 & 10358 \\
\hline Palu & 6504 & 7958 & 7949 & 8267 & 9446 & 9925 \\
\hline Makassar & 6706 & 7501 & 7565 & 7690 & 9041 & 10667 \\
\hline Mamuju & 7613 & 7489 & 7876 & 8108 & 8827 & 10774 \\
\hline Kendari & 6889 & 8186 & 8283 & 8446 & 9938 & 9552 \\
\hline Ambon & 8394 & 8981 & 9381 & 10292 & 11440 & 11819 \\
\hline Ternate & 8785 & 9463 & 9757 & 10448 & 11727 & 12031 \\
\hline Jayapura & 7551 & 10205 & 10325 & 11296 & 12394 & 12376 \\
\hline Manokwari & 9285 & 9137 & 10013 & 10687 & 11189 & 12965 \\
\hline
\end{tabular}

Sumber : Badan Pusat Statistik, url :https://www.bps.go.id

Tabel 2. Data Akumulasi Harga Eceran Beras di Pasar Tradisional di 33 Kota (Rupiah/Kg)

\begin{tabular}{|c|c|c|c|}
\hline Kota Harga Eceran & Rata-rata & Kota Harga Eceran & Rata-rata \\
\hline Banda Aceh & 9206 & Mataram & 8333 \\
\hline Medan & 9296 & Kupang & 9271 \\
\hline Padang & 10970 & Pontianak & 10763 \\
\hline Pekanbaru & 10707 & Palangkaraya & 12266 \\
\hline Tanjung Pinang & 10418 & Banjarmasin & 11025 \\
\hline Jambi & 9194 & Samarinda & 10073 \\
\hline Palembang & 8937 & Manado & 9441 \\
\hline Pangkal Pinang & 9351 & Gorontalo & 8665 \\
\hline Bengkulu & 9268 & Palu & 8342 \\
\hline Bandar Lampung & 10349 & Makassar & 8195 \\
\hline Jakarta & 10431 & Mamuju & 8448 \\
\hline Bandung & 9260 & Kendari & 8549 \\
\hline Serang & 8514 & Ambon & 10051 \\
\hline Semarang & 8889 & Ternate & 10369 \\
\hline Yogyakarta & 8861 & Jayapura & 10691 \\
\hline Surabaya & 8754 & Manokwari & 10546 \\
\hline Denpasar & 9384 & & \\
\hline & & &
\end{tabular}

Setelah diakumulasikan maka akan didapatkan nilai dari seluruh populasi harga eceran beras di pasar tradisional di 33 kota. Kemudian data tersebut akan masuk ke tahapan clustering dengan menerapkan algoritma K-Means untuk mengcluster data menjadi tiga cluster.

\subsection{Centroid Data}

Dalam penerapan algoritma K-means dihasilkan nilai titik tengah atau centroid dari data yang didapat dengan ketentuan bahwa clusterisasi yang diinginkan adalah 3, Penentuan titik ini dilakukan dengan mengambil nilai terbesar (maksimum) untuk cluster tingkat populasi tinggi (C1), nilai rata-rata (average) untuk cluster tingkat populasi sedang (C2) dan nilai terkecil (minimum) untuk cluster tingkat populasi rendah (C3). Nilai titik tersebut dapat diketahui pada Tabel 3 berikut: 
Tabel 3. Centroid Data awal

\begin{tabular}{|l|c|}
\hline \multicolumn{2}{|c|}{ Centroid } \\
\hline Max (C1) & 12266 \\
\hline Average (C2) & 9600 \\
\hline Min (C3) & 8195 \\
\hline
\end{tabular}

\subsection{Clustering Data}

Dengan menggunakan centroid tersebut maka dapat dicluster data yang telah didapat menjadi 3 cluster. Proses cluster dengan mengambil jarak terdekat dari setiap data yang diolah. Dari data populasi harga eceran beras di pasar tradisional di 33 kota didapatkan pengelompokan pada iterasi 1 untuk 3 cluster tersebut. Proses pencarian jarak terpendek, pengelompokan data pada iterasi 1 dan Clustering data dapat dilihat pada tabel berikut:

Tabel 4. Perhitungan Jarak Pusat Cluster iterasi 1

\begin{tabular}{|l|c|c|c|c|c|}
\hline \multirow{2}{*}{ Kota } & Rata-rata & \multicolumn{3}{|c|}{ Iterasi 1 } & Jarak \\
\cline { 3 - 6 } & & C1 & C2 & C3 & Terpendek \\
\hline Banda Aceh & 9206 & 3.059 & 394 & 1011 & 394 \\
\hline Medan & 9296 & 2.970 & 304 & 1101 & 304 \\
\hline Padang & 10970 & 1.296 & 1369 & 2775 & 1.296 \\
\hline Pekanbaru & 10707 & 1.559 & 1107 & 2512 & 1.107 \\
\hline Tanjung Pinang & 10418 & 1.848 & 818 & 2223 & 818 \\
\hline Jambi & 9194 & 3.072 & 406 & 999 & 406 \\
\hline Palembang & 8937 & 3.329 & 664 & 742 & 664 \\
\hline Pangkal Pinang & 9351 & 2.915 & 250 & 1156 & 250 \\
\hline Bengkulu & 9268 & 2.998 & 333 & 1073 & 333 \\
\hline Bandar Lampung & 10349 & 1.917 & 748 & 2154 & 748 \\
\hline Jakarta & 10431 & 1.835 & 831 & 2236 & 831 \\
\hline Bandung & 9260 & 3.005 & 340 & 1065 & 340 \\
\hline Serang & 8514 & 3.752 & 1087 & 319 & 319 \\
\hline Semarang & 8889 & 3.377 & 711 & 694 & 694 \\
\hline Yogyakarta & 8861 & 3.405 & 739 & 666 & 666 \\
\hline Surabaya & 8754 & 3.512 & 847 & 559 & 559 \\
\hline Denpasar & 9384 & 2.882 & 217 & 1189 & 217 \\
\hline Mataram & 8333 & 3.933 & 1268 & 138 & 138 \\
\hline Kupang & 9271 & 2.994 & 329 & 1076 & 329 \\
\hline Pontianak & 10763 & 1.503 & 1162 & 2568 & 1.162 \\
\hline Palangkaraya & 12266 & - & 2665 & 4071 & - \\
\hline Banjarmasin & 11025 & 1.241 & 1424 & 2830 & 1.241 \\
\hline Samarinda & 10073 & 2.193 & 473 & 1878 & 473 \\
\hline Manado & 9441 & 2.825 & 160 & 1246 & 160 \\
\hline Gorontalo & 8665 & 3.601 & 935 & 470 & 470 \\
\hline Palu & 8342 & 3.924 & 1259 & 147 & 147 \\
\hline Makassar & 8195 & 4.071 & 1405 & 0 & - \\
\hline Mamuju & 8448 & 3.818 & 1153 & 253 & 253 \\
\hline Kendari & 8549 & 3.717 & 1051 & 354 & 354 \\
\hline Ambon & 10051 & 2.215 & 451 & 1856 & 451 \\
\hline Ternate & 10369 & 1.897 & 768 & 2174 & 768 \\
\hline Jayapura & 10691 & 1.575 & 1091 & 2496 & 1.091 \\
\hline Manokwari & 1.720 & 946 & 2351 & 946 \\
\hline
\end{tabular}


Tabel 5. Hasil Pengelompokan Iterasi 1

\begin{tabular}{|l|c|c|c|l|c|c|c|}
\hline \multicolumn{1}{|c|}{ Kota } & C1 & C2 & C3 & \multicolumn{1}{|c|}{ Kota } & C1 & C2 & C3 \\
\hline Banda Aceh & & 1 & & Mataram & & & 1 \\
\hline Medan & & 1 & & Kupang & & 1 & \\
\hline Padang & 1 & & & Pontianak & & 1 & \\
\hline Pekanbaru & & 1 & & Palangkaraya & 1 & & \\
\hline Tanjung Pinang & & 1 & & Banjarmasin & 1 & & \\
\hline Jambi & & 1 & & Samarinda & & 1 & \\
\hline Palembang & & 1 & & Manado & & 1 & \\
\hline Pangkal Pinang & & 1 & & Gorontalo & & & 1 \\
\hline Bengkulu & & 1 & & Palu & & & 1 \\
\hline Bandar Lampung & & 1 & & Makassar & & & 1 \\
\hline Jakarta & & 1 & & Mamuju & & & 1 \\
\hline Bandung & & 1 & & Kendari & & & 1 \\
\hline Serang & & & 1 & Ambon & & 1 & \\
\hline Semarang & & & 1 & Ternate & & 1 & \\
\hline Yogyakarta & & & 1 & Jayapura & & 1 & \\
\hline Surabaya & & & 1 & Manokwari & & 1 & \\
\hline Denpasar & & 1 & & & & & \\
\hline
\end{tabular}

Proses $K$-means akan beriterasi sampai nilai pengelompokan data sama dengan nilai pengelompokan data sebelumnya. Selanjutnya dicari nilai tengah atau centroid, proses sama dilakukan dengan mencari jarak terdekat. Proses pencarian jarak terpendek [11]-[14], pengelompokan data pada iterasi terakhir dan clustering data dapat dilihat pada tabel berikut:

Tabel 6. Centroid Data iterasi 6

\begin{tabular}{|l|c|}
\hline \multicolumn{2}{|c|}{ Centroid } \\
\hline Max (C1) & 10776 \\
\hline Average (C2) & 9436 \\
\hline Min (C3) & 8590 \\
\hline
\end{tabular}

Tabel 7. Perhitungan Jarak Pusat Cluster iterasi 6

\begin{tabular}{|l|c|c|c|c|c|}
\hline \multirow{2}{*}{ Kota } & Rata-Rata & \multicolumn{3}{|c|}{ Iterasi 6 } & Jarak \\
\cline { 3 - 6 } & & C1 & C2 & C3 & Terpendek \\
\hline Banda Aceh & 9206 & 1569 & 230 & 617 & 230 \\
\hline Medan & 9296 & 1480 & 140 & 707 & 140 \\
\hline Padang & 10970 & 194 & 1534 & 2380 & 194 \\
\hline Pekanbaru & 10707 & 69 & 1271 & 2117 & 69 \\
\hline Tanjung Pinang & 10418 & 358 & 982 & 1829 & 358 \\
\hline Jambi & 9194 & 1582 & 242 & 605 & 242 \\
\hline Palembang & 8937 & 1839 & 499 & 347 & 347 \\
\hline Pangkal Pinang & 9351 & 1425 & 85 & 761 & 85 \\
\hline Bengkulu & 9268 & 1508 & 168 & 678 & 168 \\
\hline Bandar Lampung & 10349 & 427 & 913 & 1759 & 427 \\
\hline Jakarta & 10431 & 345 & 995 & 1842 & 345 \\
\hline Bandung & 9260 & 1515 & 176 & 671 & 176 \\
\hline Serang & 8514 & 2262 & 922 & 76 & 76 \\
\hline Semarang & 8889 & 1887 & 547 & 299 & 299 \\
\hline
\end{tabular}

Algoritma K-Means pada Pengelompokan Harga Eceran Beras (Theresia Siburian) | 933 


\begin{tabular}{|l|c|c|c|c|c|}
\hline \multirow{2}{*}{ Kota } & \multirow{2}{*}{ Rata-Rata } & \multicolumn{3}{|c|}{ Iterasi 6 } & Jarak \\
\cline { 3 - 6 } & & C1 & C2 & C3 & Terpendek \\
\hline Yogyakarta & 8861 & 1915 & 575 & 272 & 272 \\
\hline Surabaya & 8754 & 2022 & 682 & 164 & 164 \\
\hline Denpasar & 9384 & 1392 & 52 & 794 & 52 \\
\hline Mataram & 8333 & 2443 & 1103 & 257 & 257 \\
\hline Kupang & 9271 & 1504 & 165 & 682 & 165 \\
\hline Pontianak & 10763 & 13 & 1327 & 2173 & 13 \\
\hline Palangkaraya & 12266 & 1490 & 2830 & 3676 & 1490 \\
\hline Banjarmasin & 11025 & 249 & 1589 & 2435 & 249 \\
\hline Samarinda & 10073 & 703 & 637 & 1484 & 637 \\
\hline Manado & 9441 & 1335 & 5 & 851 & 5 \\
\hline Gorontalo & 8665 & 2111 & 771 & 76 & 76 \\
\hline Palu & 8342 & 2434 & 1094 & 248 & 248 \\
\hline Makassar & 8195 & 2581 & 1241 & 395 & 395 \\
\hline Mamuju & 8448 & 2328 & 988 & 142 & 142 \\
\hline Kendari & 8549 & 2227 & 887 & 41 & 41 \\
\hline Ambon & 10051 & 725 & 615 & 1462 & 615 \\
\hline Ternate & 10369 & 407 & 933 & 1779 & 407 \\
\hline Jayapura & 10691 & 85 & 1255 & 2102 & 85 \\
\hline Manokwari & 10546 & 230 & 1110 & 1956 & 230 \\
\hline
\end{tabular}

Tabel 8. Hasil Pengelompokan Iterasi 6

\begin{tabular}{|l|c|c|c|c|c|c|c|}
\hline \multicolumn{1}{|c|}{ Kota } & C1 & C2 & C3 & Kota & C1 & C2 & C3 \\
\hline Banda Aceh & & 1 & & Mataram & & & 1 \\
\hline Medan & & 1 & & Kupang & & 1 & \\
\hline Padang & 1 & & & Pontianak & 1 & & \\
\hline Pekanbaru & 1 & & & Palangkaraya & 1 & & \\
\hline Tanjung Pinang & 1 & & & Banjarmasin & 1 & & \\
\hline Jambi & & 1 & & Samarinda & & 1 & \\
\hline Palembang & & & 1 & Manado & & 1 & \\
\hline Pangkal Pinang & & 1 & & Gorontalo & & & 1 \\
\hline Bengkulu & & 1 & & Palu & & & 1 \\
\hline Bandar Lampung & 1 & & & Makassar & & & 1 \\
\hline Jakarta & 1 & & & Mamuju & & & 1 \\
\hline Bandung & & 1 & & Kendari & & & 1 \\
\hline Serang & & & 1 & Ambon & & 1 & \\
\hline Semarang & & & 1 & Ternate & 1 & & \\
\hline Yogyakarta & & & 1 & Jayapura & 1 & & \\
\hline Surabaya & & & 1 & Manokwari & 1 & & \\
\hline Denpasar & & 1 & & & & & \\
\hline
\end{tabular}

\subsection{Analisa Data}

Pada iterai 6 pengelompokan data yang dilakukan terhadap 3 Cluster dengan iterasi 1 didapatkan hasil yang sama nilainya. Dari 33 data jumlah rata-rata harga eceran beras di pasar tradisional dapat diketahui bahwa cluster tinggi (C1) sebanyak 11 Kota untuk cluster sedang (C2) sebanyak 11 Kota dan untuk cluster rendah (C3) sebanyak 11 Kota. 


\section{KESIMPULAN}

Berdasarkan penelitian yang telah dilakukan, algoritma K-Means mampu mengelompokan rata-rata harga eceran beras di pasar tradisional ke dalam 3 cluster, Dalam penerapan algoritma K-means dihasilkan nilai titik tengah atau centroid dari data yang didapat dengan ketentuan clusterisasi yang dilakukan dari 3 cluster tersebut, Penentuan titik ini dilakukan dengan mengambil nilai terbesar (maksimum) untuk cluster tingkat populasi tinggi (C1), nilai rata-rata (average) untuk cluster tingkat populasi sedang (C2) dan nilai terkecil (minimum) untuk cluster tingkat populasi rendah (C3). Centroid data untuk cluster tingkat populasi tinggi 10.776, Cetroid data untuk cluster tingkat populasi sedang 9.436 dan Cetroid data untuk cluster tingkat populasi rendah 8.590. Sehingga diperoleh penilaian berdasarkan pengelompokan jumlah rata-rata harga eceran beras di pasar tradisional di 33 kota dengan cluster tinggi (C1) sebanyak 11 Kota yakni Padang, Pekanbaru, Tanjung Pinang, Bandar Lampung, Jakarta, Pontianak, Palangkaraya, Banjarmasin, Ternate, Jayapura dan Manokwari untuk cluster sedang (C2) sebanyak 11 Kota dan untuk cluster rendah (C3) sebanyak 11 Kota. Dari hasil penelitian ini dapat dijadikan masukan bagi pemerintah khususnya di kota, agar kota yang masuk kedalam cluster tinggi dapat menormalisasikan harga eceran beras di tiap-tiap kota.

\section{DAFTAR PUSTAKA}

[1] D. Mining and K. Clustering, "Penerapan Algoritma K-Means Clustering Untuk Pengelompokkan Penyebaran Diare Di Kabupaten Langkat,” pp. 108-119.

[2] P. Studi, S. Informasi, S. Tunas, and B. Pematangsiantar, "PEMANFAATAN DATA MINING PENEMPATAN BUKU ( Study Kasus : SMA NEGERI 1 SIDAMANIK ) Friskila Parhusip,” vol. 3, no. 1, pp. 61-65, 2019.

[3] L. Teori, “( K-MEANS ALGORITHM IMPLEMENTATION FOR CLUSTERING OF PATIENTS DISEASE IN KAJEN CLINIC OF PEKALONGAN ) Anindya Khrisna Wardhani Magister Sistem Informasi Universitas Diponegoro," vol. 14, pp. 30-37, 2016.

[4] S. Kasus, D. I. Toko, and A. D. I. Bangunan, "KLASTERISASI PENJUALAN ALAT-ALAT BANGUNAN MENGGUNAKAN METODE K-MEANS,” vol. 1, no. 2, pp. 83-91, 2018.

[5] I. Sudono et al., "PENGELOMPOKAN PRODUKSI PADI NASIONAL DENGAN PENDEKATAN DATA MINING KONSEP K-MEANS CLUSTERING NATIONAL RICE PRODUCTION IN MINING DATA APPROACH CONCEPT OF K-MEANS," vol. 8, no. 2, pp. 72-89, 2013.

[6] F. L. Sibuea, A. Sapta, S. Informasi, and S. Royal, "PEMETAAN SISWA BERPRESTASI MENGGUNAKAN METODE K-MEANS CLUSTERING,” vol. IV, no. 1, 2017.

[7] A. S. ARIBOWO, "E-elearning Cerdas Dengan Personalisasi Menggunakan Teknik Data Mining dan Decision Support System," Seminar Nasional Informatika 2010 (semnasIF 2010), vol. 2010, no. semnasIF, 2010.

[8] B. M. Metisen and H. L. Sari, "ANALISIS CLUSTERING MENGGUNAKAN METODE K-MEANS DALAM PENGELOMPOKKAN PENJUALAN PRODUK PADA SWALAYAN FADHILA,” vol. 11, no. 2, pp. 110-118, 2015.

[9] P. Beasiswa, B. Misi, and D. I. Polbeng, "K-MEANS UNTUK MENENTUKAN CALON," vol. 1, no. $1,2016$.

[10] L. Maulida, P. Studi, and M. Informatika, "KUNJUNGAN WISATAWAN KE OBJEK WISATA UNGGULAN DI PROV. DKI JAKARTA DENGAN K-MEANS," vol. 2, no. 3, pp. 167-174, 2018.

[11] M. G. Sadewo, A. P. Windarto, and A. Wanto, "Penerapan Algoritma Clustering dalam Mengelompokkan Banyaknya Desa/Kelurahan Menurut Upaya Antisipasi/ Mitigasi Bencana Alam Menurut Provinsi dengan K-Means," KOMIK (Konferensi Nasional Teknologi Informasi dan Komputer), vol. 2, no. 1, pp. 311-319, 2018.

[12] R. W. Sari, A. Wanto, and A. P. Windarto, "Implementasi Rapidminer dengan Metode K- 
Means (Study Kasus: Imunisasi Campak pada Balita Berdasarkan Provinsi)," KOMIK (Konferensi Nasional Teknologi Informasi dan Komputer), vol. 2, no. 1, pp. 224-230, 2018.

[13] S. Sudirman, A. P. Windarto, and A. Wanto, "Data Mining Tools | RapidMiner: K-Means Method on Clustering of Rice Crops by Province as Efforts to Stabilize Food Crops In Indonesia," IOP Conference Series: Materials Science and Engineering, vol. 420, no. 12089, pp. 1-8, 2018.

[14] I. Parlina, A. P. Windarto, A. Wanto, and M. R. Lubis, "Memanfaatkan Algoritma K-Means dalam Menentukan Pegawai yang Layak Mengikuti Asessment Center untuk Clustering Program SDP," CESS (Journal of Computer Engineering System and Science), vol. 3, no. 1, pp. 87-93, 2018. 